\title{
NPM1 alternative transcripts are upregulated in acute myeloid and lymphoblastic leukemia and their expression level affects patient outcome
}

Luiza Handschuh ${ }^{1,2^{*}}$ D, Pawel Wojciechowski ${ }^{1,4+}$, Maciej Kazmierczak ${ }^{2 \dagger}$, Malgorzata Marcinkowska-Swojak', Magdalena Luczak ${ }^{1,3}$, Krzysztof Lewandowski $^{2}$, Mieczyslaw Komarnicki' ${ }^{2}$ Jacek Blazewicz ${ }^{1,4}$,

Marek Figlerowicz ${ }^{1,4}$ and Piotr Kozlowski ${ }^{1,3}$

\begin{abstract}
Background: Expression of the NPM1 gene, encoding nucleophosmin, is upregulated in cancers. Although more than ten NPM1 transcripts are known, the reports were usually limited to one predominant transcript. In leukemia, the NPM1 expression has not been widely studied so far. In acute myeloid leukemia (AML), the mutational status of the gene seems to play a pivotal role in carcinogenesis. Therefore, the aim of the study was to quantify alternative NPM1 transcripts in two types of acute leukemia, AML and ALL (acute lymphoblastic leukemia).

Methods: Using droplet digital PCR, we analyzed the levels of three protein-coding NPM1 transcripts in 66 samples collected from AML and ALL patients and 16 control samples. Using RNA-seq, we detected 8 additional NPM1 transcripts, including non-coding splice variants with retained introns. For data analysis, Welch two sample t-test, Pearson's correlation and Kaplan-Meier analysis were applied.
\end{abstract}

Results: The levels of the particular NPM1 transcripts were significantly different but highly correlated with each other in both leukemia and control samples. Transcript NPM1.1, encoding the longest protein (294 aa), had the highest level of accumulation and was one of the most abundant transcripts in the cell. Comparing to NPM1.1, the levels of the NPM1.2 and NPM1.3 transcripts, encoding a 265-aa and 259-aa proteins, were 30 and 3 times lower, respectively. All three NPM1 transcripts were proportionally upregulated in both types of leukemia compared to control samples. In AML, the levels of NPM1 transcripts decreased in complete remission and increased again with relapse of the disease. Low levels of NPM1.1 and NPM1.3 were associated with better prognosis. The contribution of non-coding transcripts to the total level of NPM1 gene seemed to be marginal, except for one short 5-end transcript accumulated at high levels in AML and control cells. Aberrant proportions of particular NPM1 splice variants could be linked to abnormal expression of genes encoding alternative splicing factors.

Conclusions: The levels of the studied NPM1 transcripts were different but highly correlated with each other. Their upregulation in AML and ALL, decrease after therapy and association with patient outcome suggests the involvement of elevated NPM1 expression in the acute leukemia pathogenesis.

Keywords: NPM1, Expression, AML, ALL, Splice variants, Quantitative transcript analysis

*Correspondence: luizahan@ibch.poznan.pl

${ }^{\dagger}$ Pawel Wojciechowski and Maciej Kazmierczak have contributed equally

to this work

${ }^{1}$ European Centre for Bioinformatics and Genomics, Institute

of Bioorganic Chemistry, Polish Academy of Sciences, Noskowskiego

12/14, 61-704 Poznan, Poland

Full list of author information is available at the end of the article

(c) The Author(s) 2018. This article is distributed under the terms of the Creative Commons Attribution 4.0 International License (http://creativecommons.org/licenses/by/4.0/), which permits unrestricted use, distribution, and reproduction in any medium, provided you give appropriate credit to the original author(s) and the source, provide a link to the Creative Commons license, and indicate if changes were made. The Creative Commons Public Domain Dedication waiver (http://creativecommons.org/ publicdomain/zero/1.0/) applies to the data made available in this article, unless otherwise stated. 


\section{Background}

Nucleophosmin (NPM), also known as nucleolar phosphoprotein B23, nucleolar protein NO38 or numatrin, is involved in a wide spectrum of essential cell processes, including ribosome biogenesis and export, control of centrosome duplication, protein chaperoning, histone and nucleosome assembly, cell proliferation, DNA repair and regulation of genome stability through interaction with tumor suppressors p53 and ARF (alternative reading frame) $[1,2]$. The protein constantly moves between the nucleus and the cytoplasm, but its major localization is the nucleolus where ribosome assembly occurs [3].

The ubiquitously expressed and evolutionarily conserved gene encoding NPM, NPM1 (Gene ID 4869, mapped at 5q35.1, genomic NCBI Reference Sequence NG_016018.1, Ensembl ENSG00000181163), is mutated in $25-35 \%$ of adult patients with primary acute myeloid leukemia (AML) and 46-64\% of adult patients with normal karyotype AML (NK-AML) [3-5]. A mutation, usually an out-of-frame tetranucleotide insertion in the last (12th) NPM1 exon, changes the C-terminus of the protein and causes aberrant cytoplasmic accumulation of the protein $(\mathrm{NPMc}+)[1,3,5]$. NPMc + AML reveals unique biological and clinical features and distinct mRNA and miRNA expression profiles [6-8]. The presence of an NPM1 mutation without concomitant FLT3-ITD (FMSlike tyrosine kinase 3-internal tandem duplication) in NK-AML patients has been associated with a favorable prognosis [9-11]. Therefore, the World Health Organization (WHO) has recommended distinguishing AML with an NPM1 mutation as a separate entity $[12,13]$. Numerous tests detecting NPM1 mutations have been developed [14-18]. In other human neoplasms, mutations in the NPM1 gene are rare. Instead, overexpression of the NPM1 gene is frequently observed in different solid tumors, e.g., ovarian [19], prostate [20], colon [21, 22], bladder [23], thyroid [24], lung [25] and liver [26, 27] cancers. High NPM1 expression can be treated as an early marker of proliferative activity, preceding the S-phase of the cell cycle [28]. Increased NPM1 expression was also detected in human-derived leukemia cell lines [29]. However, to date, NPM1 expression in leukemia patients has rarely been reported and previous studies were conducted on a protein level or gene level without distinguishing transcript variants [30]. The exception has been a recent study by Zajac et al. [31] who focused on three protein-coding NPM1 splice variants, revealing a higher level in AML than in healthy control samples and associated a high expression of one NPM1 splice variant with a better prognosis in NK-AML patients. Nevertheless, the knowledge about NPM1 transcripts is still incomplete and unsystematic. In the literature, three NPM1 splice variants are reported, usually in the context of the protein isoforms they encode, historically named B23.1, B23.2 and B23.3 [3, 31, 32]. The corresponding transcripts are called NPM1.1, NPM1.2 and NPM1.3 by some authors $[2,33]$ or R1, R2 and R3 by others [31]. In addition, transcripts 2 and 3 are often confused. Database exploration demonstrated that more than three NPM1 splice variants exist, but the number, length and nomenclature of the transcripts are not consistent between databases (Additional file 1: Table S1). According to NCBI Gene repository, 8 NPM1 transcript variants (referred to as variants 1-8) were detected in humans, including 7 protein-coding variants. The Ensembl database lists 12 transcripts (named NPM1-201-NPM1-212), including 6 proteincoding variants. Both databases assign four transcript variants to the three main proteins mentioned above. As shown in Fig. 1, none of the transcripts comprises all 12 exons located in the genomic NPM1 sequence. The predominant protein (294 aa, $32.6 \mathrm{kDa}$ ) [26] is encoded by the transcript containing 11 exons, with exon 10 missing. Because there are two transcript variants encoding this protein, we refer to them both as NPM1.1. Another transcript, referred to here as NPM1.2, lacks exons 8 and 10 and encodes a 265 -aa protein, without an open reading frame (ORF) shift when compared to NPM1.1. The transcript referred to here as NPM1.3 lacks the last two exons (11 and 12) but maintains exon 10. It encodes a shortened protein (259 aa) with a distinct C-terminus, lacking the region containing a nucleolar localization signal (NoLS) [1].

The aim of this work was to quantify NPM1 transcripts in two types of acute leukemia, derived from different hematopoietic cell lineages: AML and ALL (acute lymphoblastic leukemia). First of all, we wanted to check whether NPM1 gene is upregulated in leukemia similarly as in other human neoplasms and whether NPM1 expression depends on the mutation status of the gene. In the case of upregulation, we were going to distinguish particular transcripts to test whether NPM1 transcripts are similarly increased in both leukemia types and which transcripts contribute the most to the change of expression. Another objective of the study was to compare NPM1 expression levels at three time points (at first diagnosis, after treatment and relapse). We were also interested in association of NPM1 expression with patient outcome.

\section{Methods \\ Samples}

Peripheral blood (PB) or bone marrow (BM) samples were collected from 66 adult patients with acute leukemias at the time of first diagnosis and from 16 adult healthy volunteers (HV). Additionally, we collected 9 samples from AML patients after therapy (T1 time 

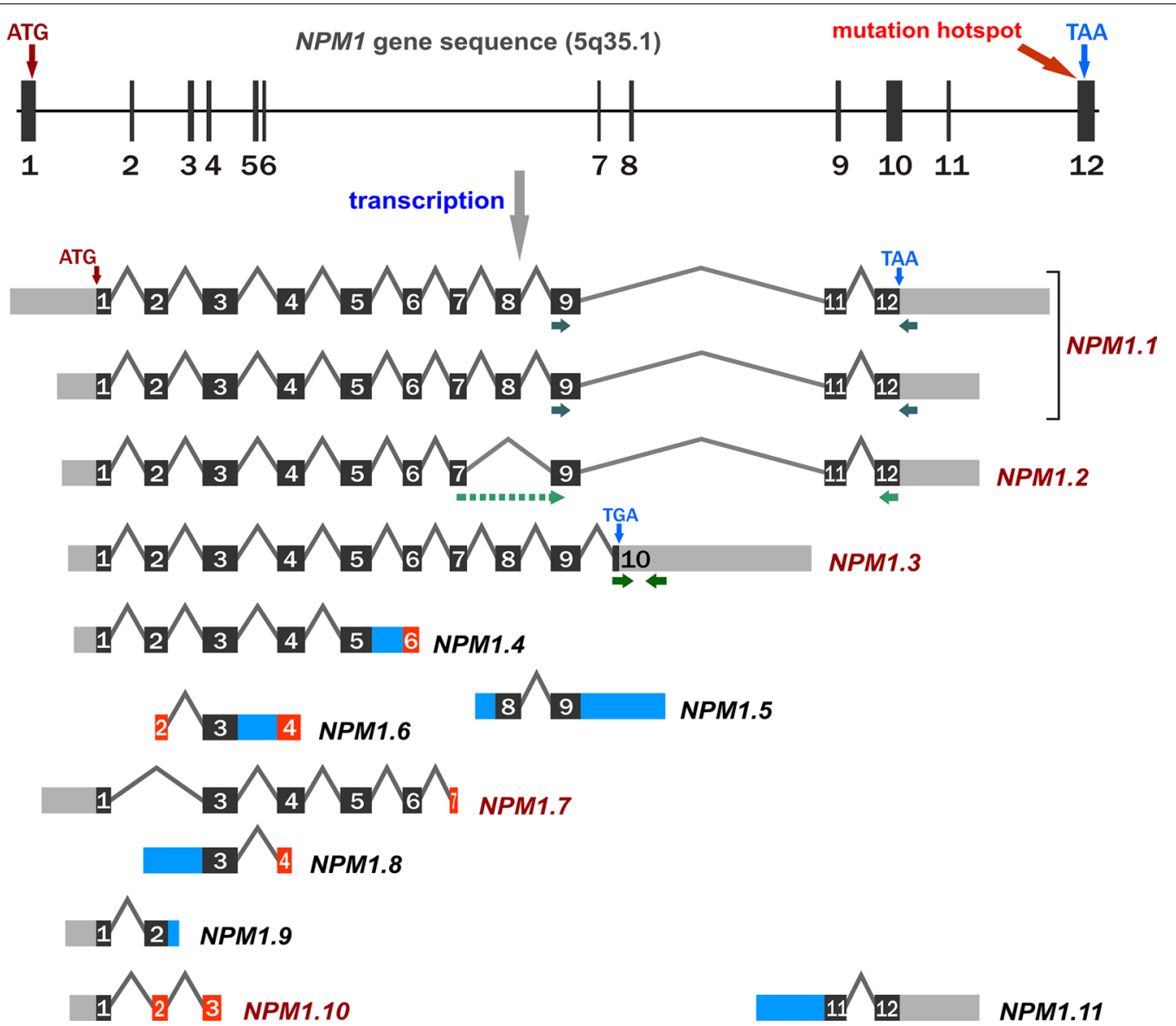

NPM1.11

Fig. 1 The schematic presentation of NPM1 gene structure and transcript variants. Exons are represented by numbered blocks. The black color marks the protein coding sequence. The red color indicates exons that are included in transcripts as partial sequences, lacking the $5^{\prime}$ or $3^{\prime}$ fragments of the exons present in the NPM1.1 transcript variant. The names of protein coding transcripts are written in dark red whereas the names of non-coding variants with retained introns/intron fragments (blue blocks) are written in black. The green arrows under transcripts indicate ddPCR primer positions. One of the NPM1.2-specific primers crosses the exon boundary (indicated by the dotted line linking exons 7 and 9)

point) and 7 samples from AML patients in relapse (T2 time point). For the time point experiment, 9 samples from AML patients at the time of first diagnosis (T0 time point) were included (Table 1, Additional file 1: Tables S2, S3). Each person provided signed informed consent for treatment and for their participation in this study. Appropriate approval was also obtained from the Bioethical Commission of the Karol Marcinkowski University of Medical Sciences. Patients were diagnosed and treated at the Department of Hematology and Bone Marrow Transplantation in the University Hospital of the Lord's Transfiguration of the University of Medical Sciences in Poznan, Poland. Fifty-seven patients were diagnosed with AML (with the following representations of the FAB subtypes: $1 \mathrm{M} 0,13 \mathrm{M} 1,23 \mathrm{M} 2,3 \mathrm{M} 3,13 \mathrm{M} 4$, and 4 M5), 8 ALL-B (acute lymphoblastic leukemia, B-cell type) and 1 patient with mixed-phenotype acute leukemia (biphenotypic acute leukemia). Standard AML therapy using cytosine arabinoside plus daunorubicin $($ " $3+7$ ") was administered to all patients to induce complete remission (CR), which was defined according to the European Leukemia Net guidelines [34]. Mononuclear cells from the peripheral blood (PBMCs) and bone marrow (BMMCs) were separated through density gradient centrifugation (Gradisol L, Aqua-Medica, Poland) and washed 3 times with $1 \times$ PBS (phosphate buffered saline, $\mathrm{Ca}$ and Mg-free, BIOMED, Poland). The cell pellet was suspended in lysis buffer from a mirVana miRNA Isolation Kit (Ambion/Thermo Fisher Scientific, Waltham, MA, USA) and immediately frozen at $-80^{\circ} \mathrm{C}$.

\section{RNA isolation and reverse transcription}

Total RNA was extracted from the PBMCs and BMMCs with a mirVana miRNA Isolation Kit (Ambion/Thermo 
Table 1 The summarized characteristics of patients

\begin{tabular}{|c|c|c|c|c|c|c|c|c|}
\hline Disease & FAB type & $\begin{array}{l}\text { Number } \\
\text { of patients } \\
\text { (F/M) }\end{array}$ & $\begin{array}{l}\text { Age median } \\
\text { (range) }\end{array}$ & $\begin{array}{l}\text { WBC mean } \\
\text { (range) }\end{array}$ & NPM1mut. & FLT3mut. & $\begin{array}{l}\text { RUNX1/ } \\
\text { RUNX1T1 }\end{array}$ & Karyotype \\
\hline \multicolumn{9}{|c|}{ ddPCR-based analysis of NPM1 transcripts at the time of diagnosis } \\
\hline \multirow[t]{6}{*}{ AML } & MO & $1(0 / 1)$ & 64 & 9.7 & - & - & - & NA (1) \\
\hline & M1 & $13(7 / 6)$ & $51(25-65)$ & $94.8(1-310.9)$ & 5 & 2 & - & $\begin{array}{l}\text { Aberrant (3) } \\
\text { NA (10) }\end{array}$ \\
\hline & M2 & $23(8 / 15)$ & $51(19-64)$ & $44.8(0.5-146.4)$ & 5 & 3 & 4 & $\begin{array}{l}\text { Normal (4) } \\
\text { Aberrant (10) } \\
\text { NA (41) }\end{array}$ \\
\hline & M3 & $3(1 / 2)$ & $60(54-67)$ & $24.8(7.2-49.1)$ & 1 & 1 & - & $\begin{array}{l}\text { Aberrant (2) } \\
\text { NA (1) }\end{array}$ \\
\hline & M4 & $13(4 / 9)$ & $52(38-75)$ & $51.8(1.9-165.2)$ & 3 & 2 & - & $\begin{array}{l}\text { Aberrant (2) } \\
\text { NA (11) }\end{array}$ \\
\hline & M5 & $4(3 / 1)$ & $40(18-57)$ & $85.6(35.1-116)$ & 1 & 1 & - & $\begin{array}{l}\text { Aberrant (1) } \\
\text { NA (3) }\end{array}$ \\
\hline ALL & ALL-B & $8(3 / 5)$ & $42.5(18-57)$ & $17.9(2.1-68.4)$ & - & - & - & $\begin{array}{l}\text { Aberrant (3) } \\
\text { NA (5) }\end{array}$ \\
\hline AML/ALL & & $1(1 / 0)$ & 55 & 16.4 & - & - & - & Aberrant (1) \\
\hline All patients & & $66(27 / 39)$ & $50(18-75)$ & $36.4(0.5-310.9)$ & 15 (10 exclusive) & 9 (4 exclusive) & 6 (4 exclusive) & $\begin{array}{l}\text { Normal (4) } \\
\text { Aberrant (22) } \\
\text { NA (40) }\end{array}$ \\
\hline \multicolumn{9}{|c|}{ RNA-seq-based analysis of NPM1 transcripts } \\
\hline \multirow[t]{2}{*}{ AML-TO } & M1 & $9(6 / 3)$ & $52(25-65)$ & $65.1(14.6-233)$ & 4 & 1 & - & $\begin{array}{l}\text { Normal (1) } \\
\text { Aberrant (3) } \\
\text { NA (5) }\end{array}$ \\
\hline & M2 & $18(7 / 11)$ & $51.5(19-64)$ & $37.5(1.34-146.4)$ & 3 & 3 & 3 & $\begin{array}{l}\text { Aberrant (10) } \\
\text { NA (8) }\end{array}$ \\
\hline AML-T1 & M2 & $1(0 / 1)$ & 64 & 21.7 & - & - & - & NA (1) \\
\hline \multicolumn{9}{|c|}{ ddPCR-based analysis of NPM1 transcripts at the three time points } \\
\hline AML-TO & M1 (3), M2 (6) & $9(3 / 6)$ & $52(19-64)$ & $59.9(11-129.2)$ & 2 & 2 & 2 & $\begin{array}{l}\text { Aberrant (5) } \\
\text { NA (4) }\end{array}$ \\
\hline AML-T1 & M1 (1), M2 (8) & $9(3 / 6)$ & $56(20-64)$ & $17.9(2.3-35.4)$ & - & - & - & NA (9) \\
\hline AML-T2 & M1 (3), M2 (4) & $7(4 / 3)$ & $54(20-65)$ & $15.9(6.6-29.9)$ & 2 & - & 1 & NA (7) \\
\hline
\end{tabular}

FLT3 mut. FLT3-ITD (internal tandem duplication in the FLT3 gene), RUNX1/RUNX1T fusion gene, result of $\mathrm{t}(8 ; 21)$ translocation, NA data not available, AML-TO AML at the time of first diagnosis, AML-T1 AML after therapy, AML-T2 AML at the relapse

Fisher Scientific) and DNase-treated (TURBO DNAfree kit, Ambion/Thermo Fisher Scientific). RNA integrity was evaluated using a Bioanalyzer 2100 and a Total RNA Nano Assay (Agilent Technologies, Santa Clara, CA, USA). Only RNAs with RIN (RNA Integrity Number) $\geq 7$ were used for the analysis. DNA-free RNA (up to $2.5 \mu \mathrm{g}$ per sample) was reverse transcribed using SuperScript III RT and oligo(dT) (Invitrogen, Carlsbad, CA, USA). The reaction mixtures $(20 \mu \mathrm{l}$ vol $)$ were incubated for $1.5 \mathrm{~h}$ at $50{ }^{\circ} \mathrm{C}$. After reverse transcription, the samples were incubated for $20 \mathrm{~min}$ at $70{ }^{\circ} \mathrm{C}$ with $10 \mu \mathrm{l}$ of $1 \mathrm{M} \mathrm{NaOH}$. Then, $10 \mu \mathrm{l}$ of $1 \mathrm{M} \mathrm{HCl}$ was added for neutralization, and the cDNA was precipitated overnight at $-20{ }^{\circ} \mathrm{C}$ with $100 \mu \mathrm{l}(2.5 \mathrm{vol})$ of $96 \%$ ethanol and $4 \mu \mathrm{l}(1 / 10 \mathrm{vol}$.) of $3 \mathrm{M}$ sodium acetate, $\mathrm{pH}$ 5.2. The centrifuged pellet was washed twice with $70 \%$ ethanol and dissolved in $50 \mu \mathrm{l}$ of DEPC- $\mathrm{H}_{2} \mathrm{O}$.

\section{Primer design}

Due to the ddPCR product length limitation, significant sequence overlap between NPM1 transcripts and high sequence homology with another human gene, CLEC2D, we were not able to design a pair of primers unique for each NPM1 transcript. In the end, we designed three pairs of primers: one specific for NPM1.2, a second specific for NPM1.3 and a third recognizing two transcripts, NPM1.1 and NPM1.2 (Additional file 1: Table S4, Fig. 1). One of the NPM1.2-specific primers crossed the exon boundary. After data collection, we subtracted the quantity of the NPM1.2-specific product from the result obtained in a reaction with primer pairs common for NPM1.1 and NPM1.2. As a reference gene, we used PGK1 (NM_000291.3, Gene ID 5230), coding for Homo sapiens phosphoglycerate kinase 1, selected as one of the most stable genes in our earlier qPCR-based analyses [30]. 


\section{Droplet digital PCR}

Quantitative PCR was performed using a QX200 Droplet Digital PCR system and QX200 EvaGreen ddPCR Supermix (Bio-Rad, Hercules, CA, USA). The reaction volume was $20 \mu \mathrm{l}$, with a primer concentration of $250 \mathrm{nM}$, and the cDNA concentration was optimized for each sample. The PCR conditions were as follows: initial denaturation $\left(95{ }^{\circ} \mathrm{C}, 5 \mathrm{~min}\right), 40$ cycles of denaturation $\left(95^{\circ} \mathrm{C}, 30 \mathrm{~s}\right)$, annealing $\left(58^{\circ} \mathrm{C}, 30 \mathrm{~s}\right)$ and elongation $\left(72{ }^{\circ} \mathrm{C}, 45 \mathrm{~s}\right)$, cooling $\left(4{ }^{\circ} \mathrm{C}, 5 \mathrm{~min}\right)$, final denaturation $\left(90^{\circ} \mathrm{C}, 5 \mathrm{~min}\right)$ and final hold $\left(12{ }^{\circ} \mathrm{C}\right)$. The temperature ramping rate was $2{ }^{\circ} \mathrm{C} / \mathrm{s}$. The data were analyzed with a QX200 Droplet Reader and processed in Quanta Soft v. 1.5.38.1118 (BioRad). The level of each NPM1 transcript was calculated by the Quanta Soft program as a ratio of NPM1 droplet number to the number of $P G K 1$ droplets counted in a single reaction. For each sample, at least two replicate experiments were performed for each NPM1 transcript. The ratio values from replicate experiments were averaged.

\section{Statistical analysis}

All statistical analyses and plots were made in $\mathrm{R}$ ver. 3.4.1 and R Studio ver. 1.0.153. The following R packages were used: base, ggplot2, ggcorrplot, plyr, reshape2, ggsignif, ggpubr, Hmisc, and survival. Welch two sample t-tests (unpaired or paired, dependently on the data) were applied for pairwise comparisons. To test the correlations between the expression values of two genes or between a particular gene's expression and clinical data (WBC, age and sex), Pearson's correlations were calculated. To estimate patient outcome and correlate it with NPM1 transcript levels, Kaplan-Meier analysis was applied. The differences between survival curves were tested with a log-rank test. The threshold $\mathrm{p}$ value was always set as 0.05 .

\section{RNA-seq data analysis}

RNA-seq was performed with a Genome Analyzer IIx (Illumina, San Diego, CA, USA). Up to $4 \mu \mathrm{g}$ of total RNA extracted from PBMCs or BMMCs was used to prepare sequencing libraries with the TruSeq RNA Sample Prep Kit (Illumina). Ten pM-indexed libraries were sequenced on a single-read flow cell (TruSeq SR Cluster Kit v2 cBot, Illumina), two libraries per lane, with 72-nt long reads. The data were processed by RSEM ver. 1.3.0 for transcript quantification at the gene and gene isoform level. RSEM automatically ran STAR aligner (ver. 2.5.3a) for mapping reads to a reference genome (Homo_sapiens. GRCh38.87). For the majority of samples, only $1-2 \%$ of reads could not be aligned to the reference genome. The levels of each isoform expression were normalized first for gene length, then for sequencing depth to obtain TPM values.

\section{Results \\ Analysis of NPM1 transcript levels in acute leukemia at the time of diagnosis}

To measure the levels of NPM1 transcripts in AML and ALL patients, we used the droplet digital PCR (ddPCR) method, allows for the absolute quantification of nucleic acid molecules in an analyzed sample [35]. To minimize the technical bias, each NPM1 transcript was measured together with a reference gene (PGK1) in a single reaction (Additional file 1: Figure S1). In total, we analyzed the levels of three NPM1 transcripts, NPM1.1, NPM1.2 and NPM1.3, in 66 mononuclear cell samples (extracted from peripheral blood, $\mathrm{PB}$, or bone marrow, $\mathrm{BM}$ ) collected at the time of the first diagnosis from adult patients with acute leukemia and from 16 adult healthy volunteers (HV). Patient samples included 57 AML, 8 ALL and one biphenotypic leukemia (Table 1, Additional file 1: Table S2). Analysis of ddPCR results revealed the evident differences in the levels of the particular NPM1 transcripts in all samples, either leukemia or HV (Fig. 2a, b, Table 2). All NPM1 transcripts were increased in leukemia compared to HV. The proportions between levels of particular transcripts were similar in leukemia and HV. The most abundant transcript was NPM1.1, whose median level was approximately 30 times higher than the median level of NPM1.2 and approximately three times higher than the median level of NPM1.3. Because the transcript levels did not follow Gaussian distribution, we subjected the data to $\log _{10}$-transformation prior to further statistical analysis. Nevertheless, the differences between the levels of particular transcripts and the differences between leukemia and HV were statistically significant before and after data transformation, which was supported by the appropriate tests. As shown in Fig. 2c-e, the levels of the studied NPM1 transcripts were also highly correlated, which was reflected by high Pearson correlation coefficients (0.89 for NPM1.1 and NPM1.3; 0.86 for NPM1.1 and NPM1.2; 0.86 NPM1.2 and NPM1.3).

After dividing the leukemia samples into AML and ALL, we noted similar levels of all NPM1 transcripts in both types of leukemia. Consequently, differences were observed between each disease and HV (Fig. $3 \mathrm{a}-\mathrm{c}$ ). Similarly, we did not observe significant differences in NPM1 transcript levels between AML FAB subtypes (Additional file 1: Figure S2A-C). Because the studied cell samples were extracted from $\mathrm{PB}$ or $\mathrm{BM}$, we tested whether NPM1 transcript levels depended on tissue type. Comparing the patient samples, we found a significantly higher level of 

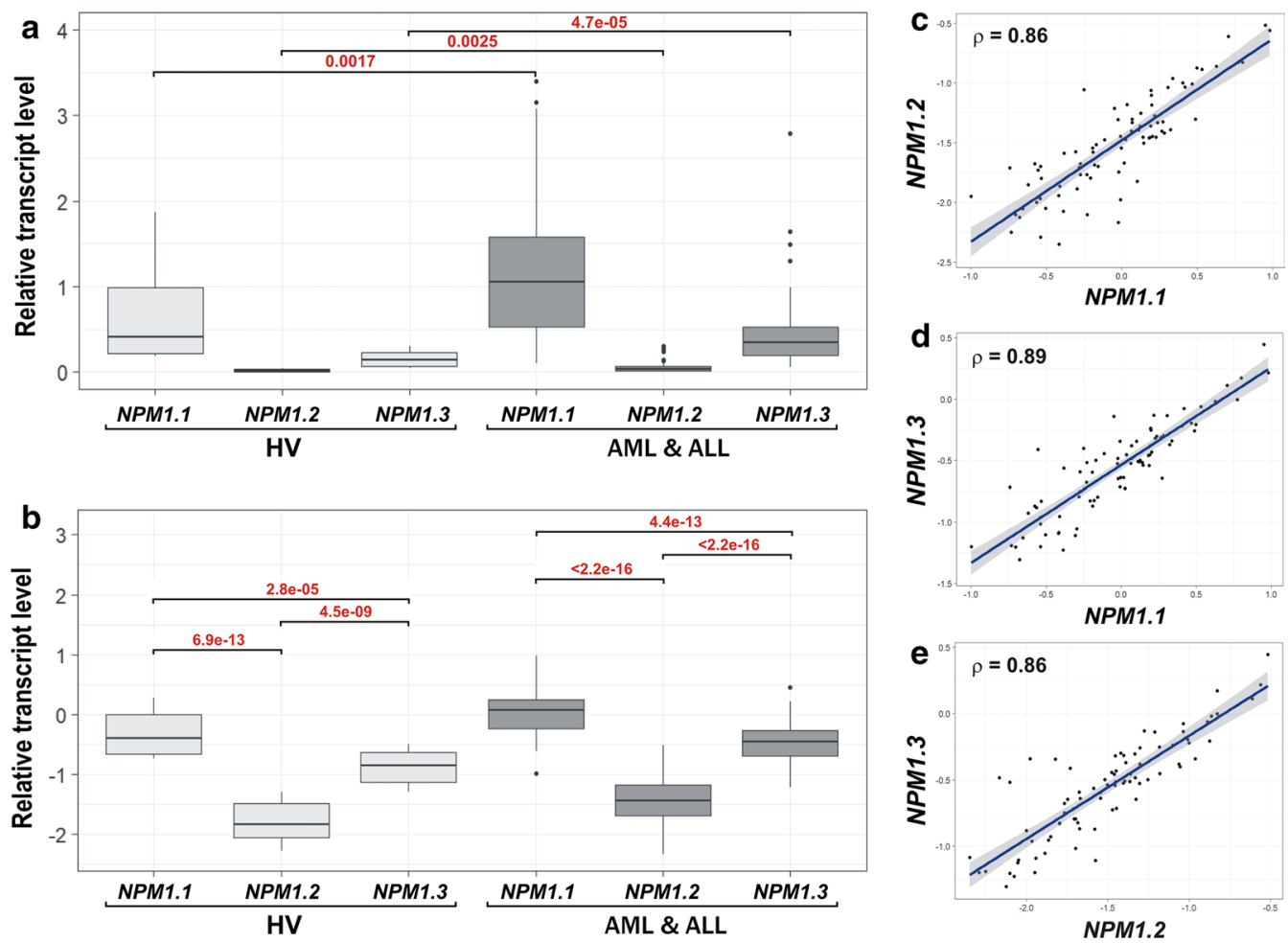

Fig. 2 The comparison of three NPM1 transcript levels in leukemia and HV. The results of ddPCR data analysis performed on the set of 66 acute leukemia samples and $16 \mathrm{HV}$ samples, prior to (a) and after the logarithmic data transformation (b-e). To compare transcript levels before and after data transformation, a Wilcoxon test and unpaired t-test were used, respectively. Included p values indicate statistically significant differences. Correlation plots $(\mathbf{c}, \mathbf{d})$ include Pearson correlation coefficients

Table 2 Median expression of three protein-coding NPM1 transcripts in leukemia and HV, and relationships between particular transcript levels

\begin{tabular}{lllllll}
\hline & $\begin{array}{l}\text { NPM1.1 median } \\
\text { level }\end{array}$ & $\begin{array}{l}\text { NPM1.2 median } \\
\text { level }\end{array}$ & $\begin{array}{l}\text { NPM1.3 median } \\
\text { level }\end{array}$ & $\begin{array}{l}\text { NPM1.1/NPM1.2 ratio } \\
\text { NPM1.1/NPM1.3 ratio }\end{array}$ & $\begin{array}{l}\text { NPM1.3/NPM1.2 } \\
\text { ratio }\end{array}$ \\
\hline Leukemia & 1.171 & 0.035 & 0.350 & 33.5 & 3.3 & 10.0 \\
HV & 0.410 & 0.014 & 0.140 & 29.3 & 2.9 & 10.0 \\
Leukemia/HV ratio & 2.9 & 2.5 & 2.5 & 1.1 & 1.1 & 1.0
\end{tabular}

NPM1.3 transcript in BM versus $\mathrm{PB}$ (Fig. 3f). The levels of NPM1.1 and NPM1.2 did not differ between PB and BM (Fig. 3d, e).

To test whether NPM1 expression depends on the mutation status, we divided the studied leukemia samples into the following groups: (i) NPM1-mut leukemia (with a tetranucleotide insertion in exon 12 of the NPM1 gene, 15 samples) vs. leukemia without an NPM1 mutation (wt, 51 samples); (ii) FLT3-mut leukemia (with FLT3-ITD, 9 samples) vs. leukemia without a FLT3 mutation (wt, 57 samples); and (iii) leukemia with a RUNX1/ RUNX1T1 fusion gene, generated as a result of translocation $\mathrm{t}(8 ; 21)$ (4 samples) vs. leukemia samples without this translocation (wt, 62 samples). As shown in Fig. 3h, we observed a statistically significant decrease of NPM1.2 transcript in NPM1-mut samples compared to the samples without an NPM1 mutation. The level of NPM1.2 transcript in NPM1-mutated leukemia was close to the level noted for HV. The levels of NPM1.1 and NPM1.3 did not differ between leukemia samples divided according to NPM1 mutation status (Fig. $3 \mathrm{~g}$, i). We did not observe a significant impact of the FLT3 mutation on the level of NPM1 transcripts, although the level of NPM1.2 was slightly lower in FLT3-mutated samples vs. samples without this mutation (Additional file 1: Figure S2D-F). In the samples with RUNX1/RUNX1T1, the levels of 

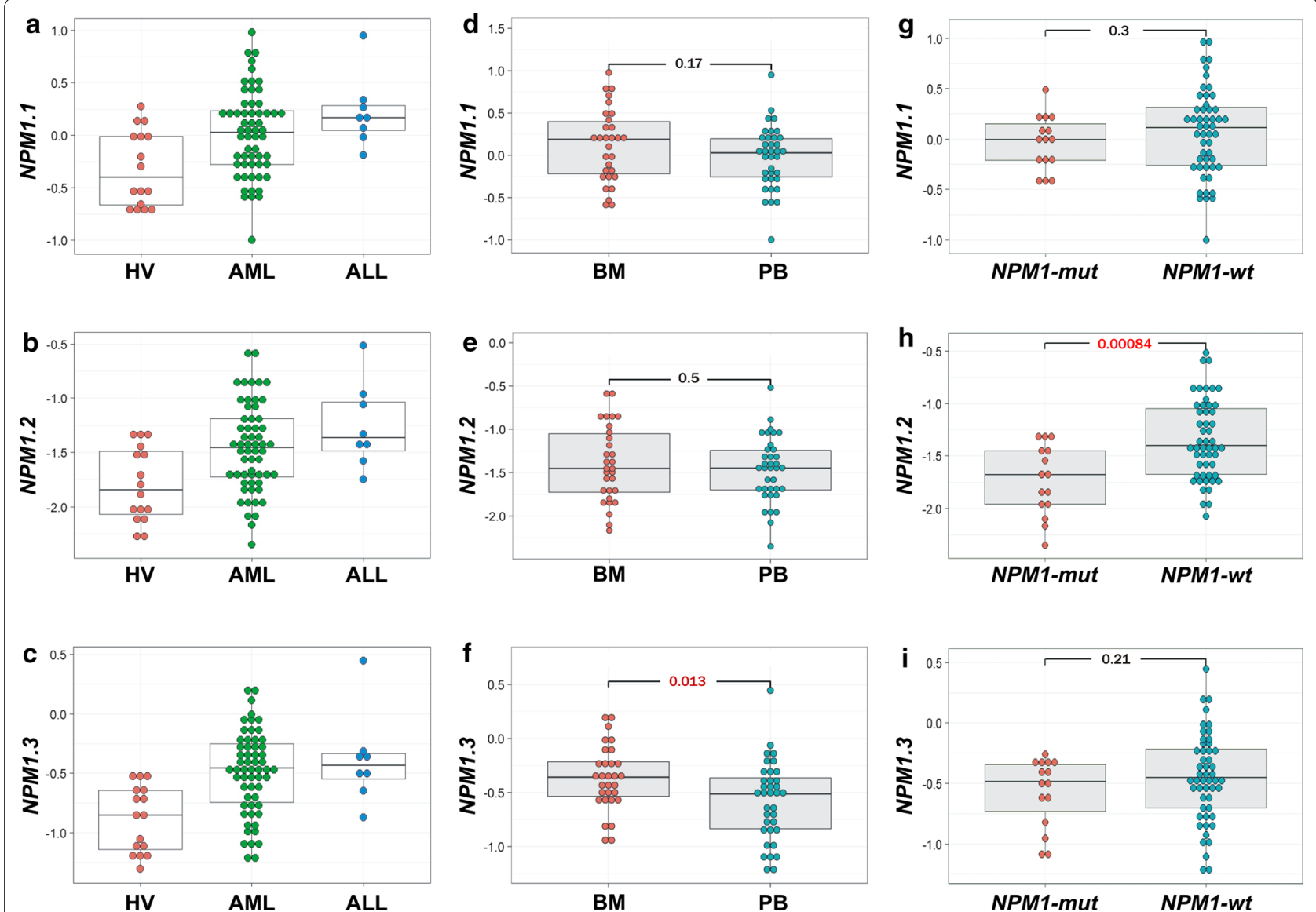

Fig. 3 The comparison of three NPM1 transcript levels in leukemia samples stratified by the disease types (a-c), source tissue type (BM or PB) (d-f), and NPM1 mutation status ( $\mathbf{g}-\mathbf{i})$. Each dot represents one sample. Background boxplots show the median (a line in the middle) and the first and third quartiles (the bottom and top of the box). Due to the small number of ALL samples, statistical analysis was not applied to the plots a-c. Plots $\mathbf{d}-\mathbf{i}$, drawn excluding $\mathrm{HV}$ samples, include t-test $\mathrm{p}$ values (statistically significant indicated in red)

NPM1 transcripts were higher compared to the samples without $\mathrm{t}(8 ; 21)$, but the number of samples with RUNX1/RUNX1T1 was too small to perform statistical analysis (Additional file 1: Figure S2G-I). As all samples with $t(8 ; 21)$ were extracted from BM cells, the plots were drawn excluding PB samples.

Analyzing the impact of the white blood cell (WBC) count, sex and age of patients, we found no influence of these variables on the level of NPM1 transcripts (Additional file 1: Table S5).

\section{Impact of NPM1 transcript levels on patient outcome}

As the patients were recruited starting from 2007, we were able to monitor their outcome for more than 10 years. Forty-seven out of 66 patients died during this time, and the remaining patients are still alive or stopped contacting the clinic. To evaluate the impact of NPM1 transcript levels measured at the time of diagnosis and other variables (mutation status, WBC, sex) on further patient outcome, we applied Kaplan-Meier analysis. In the entire group of patients, median disease-free survival (DFS) and median overall survival (OS) were equal to 2 and 12 months, respectively (Additional file 1: Figure $\mathrm{S} 3 \mathrm{~A}, \mathrm{~B})$. To analyze the impact of NPM1 transcript levels on DFS and OS, we dichotomized samples based on the median level of the particular NPM1 transcript. The results are shown in Fig. 4 and Additional file 1: Table S6. For all three NPM1 transcripts, a high level of expression was associated with shorter DFS and shorter OS. However, the differences between the two survival curves were statistically significant only for NPM1.1 and NPM1.3 levels in the case of DFS (Fig. 4a, c) and for NPM1.1 in the case of OS (Fig. 4d). NPM1 and FLT3 mutation status and sex had no impact on DFS and OS (Additional file 1: Figure S3C-F, I, J, Table S6). From the clinical features, only the WBC count seemed to be relevant for patient outcome. Patients with high WBC number had shorter DFS and OS, although the difference between DFS curves was 

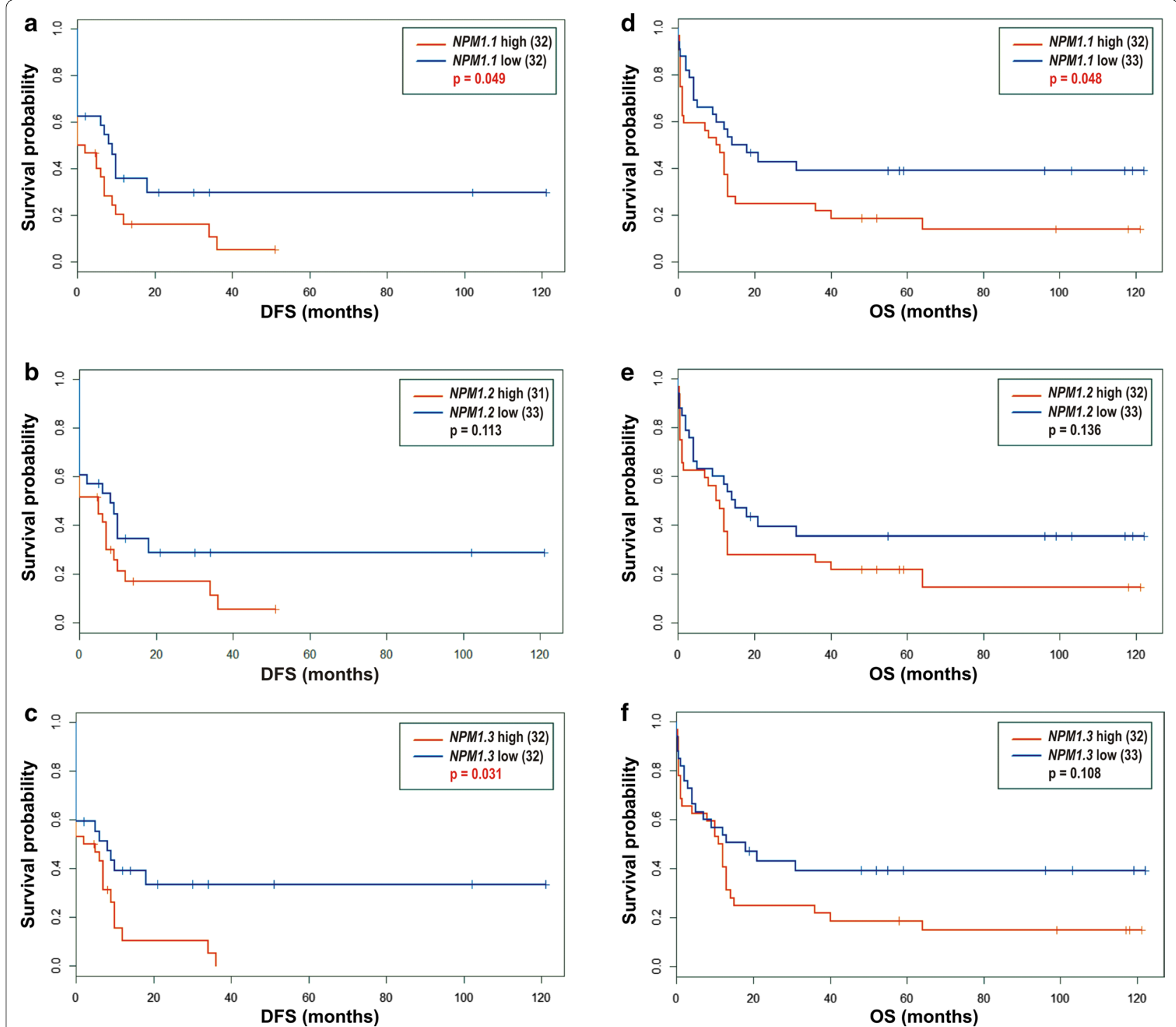

Fig. 4 Disease free survival (DFS) (a-c) and overall survival (OS) (d-f) of 66 leukemia patients divided according to the level of NPM1.1 (a, d), NPM1.2 $(\mathbf{b}, \mathbf{e})$ and NPM1.3 $(\mathbf{c}, \mathbf{f})$ transcripts. Log-rank test $\mathrm{p}$ values $<0.05$ indicate statistically significant differences between two curves

less evident $(p=0.054)$ (Additional file 1: Figure S3 G, H, Table S6).

\section{RNA-seq-based analysis of the expression of the NPM1 gene and corresponding transcripts}

To verify the results described above and extend our research to additional NPM1 transcripts, we took advantage of next generation sequencing of transcriptomes (RNA-seq). This approach enabled us to examine the expression of the NPM1 gene and corresponding transcripts on the background of other genes and transcripts present in leukemic cells. The data set included 27 samples collected at the time of diagnosis (T0 time point) from AML patients with M1 (9 patients) and M2 (18 patients) FAB types, referred to as AML-T0, and one sample collected from an AML-M2 patient 2 months after therapy (T1 time point), referred to AML-T1 (Table 1, Additional file 1: Table S2). Control samples were represented by one BM HV sample and one pool of $12 \mathrm{~PB}$ HV samples. Ranking genes according to the normalized expression values (TPM, transcripts per million) demonstrated that the NPM1 gene is one of the most abundant genes transcribed in $\mathrm{BM}$ and $\mathrm{PB}$ mononuclear cells, with median ranking position 124 in AMLT0, 188 in AML-T1 and 181.5 in HV per approximately 14,000 genes detected with TPM $>1$. The TPM of the 
NPM1 gene was equal to 1492 in AML-T0 (median), 752 in AML-T1 and 799 in HV (mean), indicating a twofold increase in leukemia at the time of diagnosis and a decrease after therapy to the level typical for HV.

Performing analysis on a transcript (gene isoform) level, we were able to detect all 11 NPM1 transcripts presented in Fig. 1, though one transcript (NPM1.10) was present in only four samples, which resulted in a median level of 0 (Table 3, Fig. 5a, b). We observed high differences between the levels of NPM1 transcripts but the contribution of particular transcripts to the total NPM1 gene expression was generally similar in all samples (Fig. 5d). Consistent with the ddPCR results, the most abundant NPM1 transcript was NPM1.1 (Fig. 5a). The median position of this transcript was equal to 160 in AML-T0, 254 in AML-T1 and 277 in HV per approximately 38,000 splice variants detected with $\mathrm{TPM}>1$. NPM1.1 was responsible for $63 \%$ of the total NPM1 gene expression in AML samples and 56\% in HV samples. NPM1.2 and NPM1.3 together constituted 8-9\% of the total NPM1 gene expression in all samples. RNA-seq data revealed a significant contribution of an additional transcript, NPM1.9 (approximately $30 \%$ in both AML and HV samples) (Fig. 5a). The remaining NPM1 transcripts were transcribed at low to marginal levels (Fig. 5b, d). The levels of the four most abundant NPM1 transcripts and NPM1.4 were highly correlated with each other (Fig. 5c).

Comparing particular AML samples, we noticed some fluctuations in the level of NPM1.2 and NPM1.9 (Fig. 5d). The extreme case was AML sample ID074, which presented the most outstanding proportion of these two splice variants (the highest level of NPM1.2 and the lowest level of NPM1.9 comparing to all other samples). To test whether the aberrant proportions of NPM1 splice variants could be linked to the expression level of splicing factor coding genes, we retrieved from our RNAseq data the results of expression of SRSF (Ser-Arg-rich Splicing Factor) gene family members. The rationale of this analysis was overexpression of SRSF1 gene, encoding an alternative splicing regulator, in different cancer types, described as one of the features promoting cancerogenesis [36]. Comparing the levels of twelve SRSF genes in

Table 3 RNA-seq-based comparison of NPM1 transcript levels in AML and HV samples

\begin{tabular}{|c|c|c|c|c|c|c|c|}
\hline \multirow[t]{2}{*}{ Transcript } & \multicolumn{2}{|l|}{ AML-T0 } & \multicolumn{2}{|l|}{ AML-T1 } & \multicolumn{2}{|l|}{ HV } & \multirow{2}{*}{$\begin{array}{l}\text { AML-TO/ } \\
\text { HV TPM } \\
\text { ratio }\end{array}$} \\
\hline & Median level (TPM) & $\begin{array}{l}\text { Contribution } \\
\text { to the total NPM1 } \\
\text { gene expression } \\
(\%)\end{array}$ & $\begin{array}{l}\text { Median } \\
\text { level } \\
\text { (TPM) }\end{array}$ & $\begin{array}{l}\text { Contribution } \\
\text { to the total NPM1 } \\
\text { gene expression } \\
(\%)\end{array}$ & Median level (TPM) & $\begin{array}{l}\text { Contribution } \\
\text { to the total NPM1 } \\
\text { gene expression } \\
\text { (\%) }\end{array}$ & \\
\hline NPM1.1 & 950.37 & 63.68 & 473.63 & 63.02 & 445.485 & 55.73 & 2.13 \\
\hline NPM1.2 & 55.36 & 3.71 & 18.14 & 2.41 & 24.655 & 3.084 & 2.25 \\
\hline NPM1.3 & 62.88 & 4.21 & 45.8 & 6.09 & 52.505 & 6.569 & 1.20 \\
\hline NPM1.4 & 1.09 & 0.073 & 0.43 & 0.057 & 1.46 & 0.183 & 0.75 \\
\hline NPM1.5 & 0.76 & 0.051 & 0.37 & 0.049 & 0.655 & 0.082 & 1.16 \\
\hline NPM1.6 & 0.71 & 0.048 & 0.5 & 0.067 & 0.53 & 0.066 & 1.34 \\
\hline NPM1.7 & 4.53 & 0.304 & 3.07 & 0.408 & 13.785 & 1.725 & 0.33 \\
\hline NPM1.8 & 0.4 & 0.027 & 0 & 0 & 0.385 & 0.048 & 1.04 \\
\hline NPM1.9 & 412.59 & 27.65 & 206.85 & 27.52 & 256.25 & 32.06 & 1.61 \\
\hline NPM1.10 & 0 & 0 & 0 & 0 & 0 & 0 & - \\
\hline NPM1.11 & 3.7 & 0.248 & 2.77 & 0.369 & 3.61 & 0.452 & 1.02 \\
\hline total & 1492.39 & 100 & 751.56 & 100 & 799.32 & 100 & - \\
\hline
\end{tabular}

(See figure on next page.)

Fig. 5 The comparison of NPM1 transcript levels estimated from the analysis of RNA-seq data. Boxplots A and B present TPM values. For clear presentation, NPM1 transcripts were divided into two plots according to the level of expression: (a) high and (b) low. Boxplots do not show 8 outliers for NPM1.1, 6 outliers for NPM1.7, and 2 outliers for NPM1.10. A correlation plot (c) shows Spearman correlation coefficients for each pair of NPM 1 transcripts, ranked according to the similarity of expression. Color intensity and the size of the circles are proportional to the correlation coefficients. Circles smaller than an empty one under the plot means not statistically significant correlation. $\mathbf{d}$ The ratio of NPM1 splice variants in particular samples. Legend is above the plot. e Expression level of SRSF8 gene, encoding one of the splicing factors from the Ser/Arg-rich protein family. Control samples are indicated in pink (BM-HV—bone marrow sample from a healthy volunteer; PB-HV—a pool of 12 peripheral blood samples from healthy volunteers) whereas AML samples in grey (ID014-ID103_AML at the time of first diagnosis, AML-T1_AML sample after therapy), except for one sample (ID074, green) with extremely higher level of SRFS8 expression 


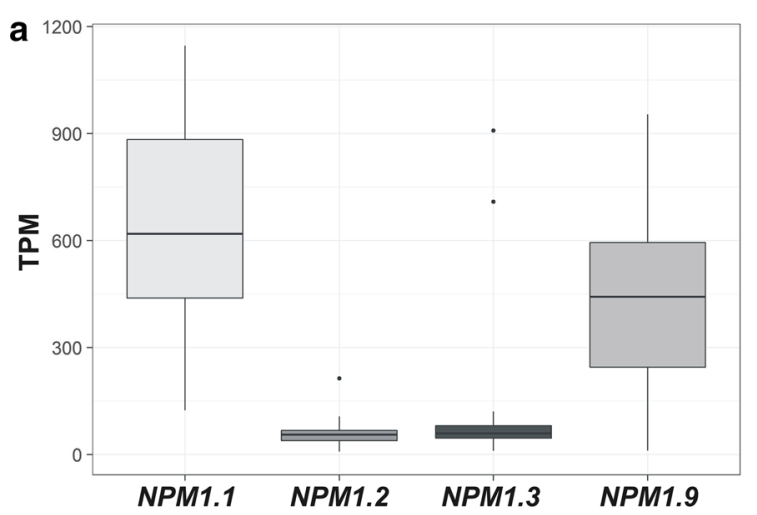

b

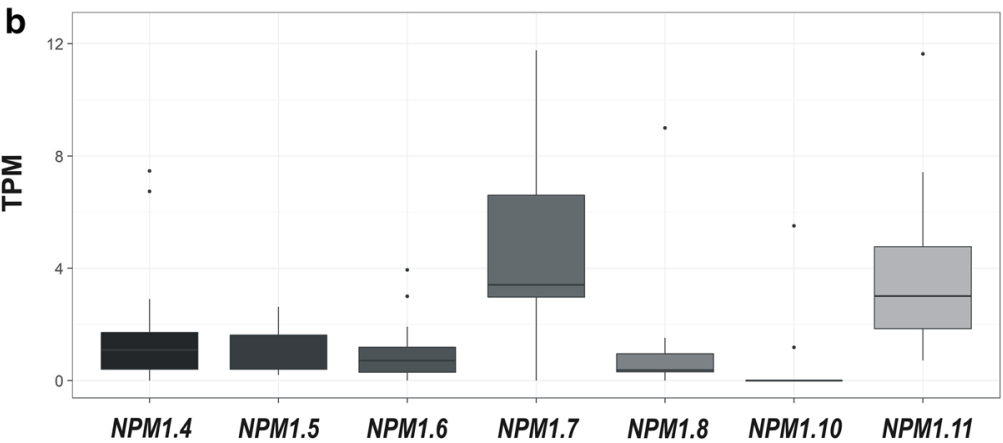

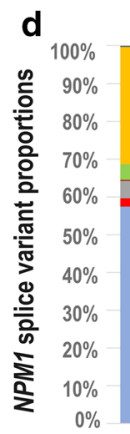

e

立 站

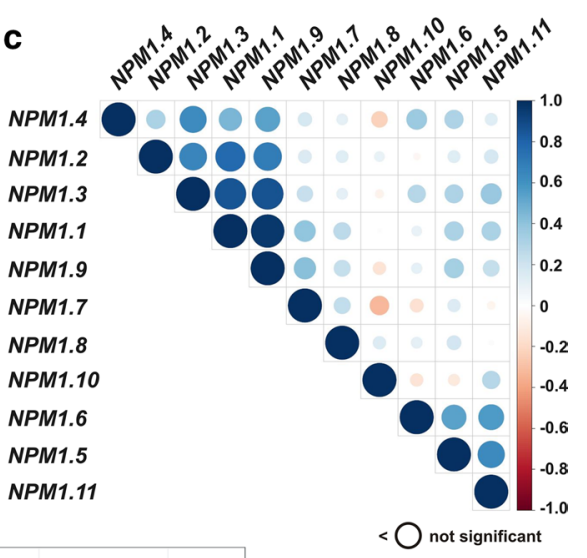

- NPM1.11

- NPM1.10

- NPM1.9

- NPM1.8

- NPM1.7

- NPM1.6

- NPM1.5

- NPM1.4

NPM1.3

- NPM1.2

NPM1.1

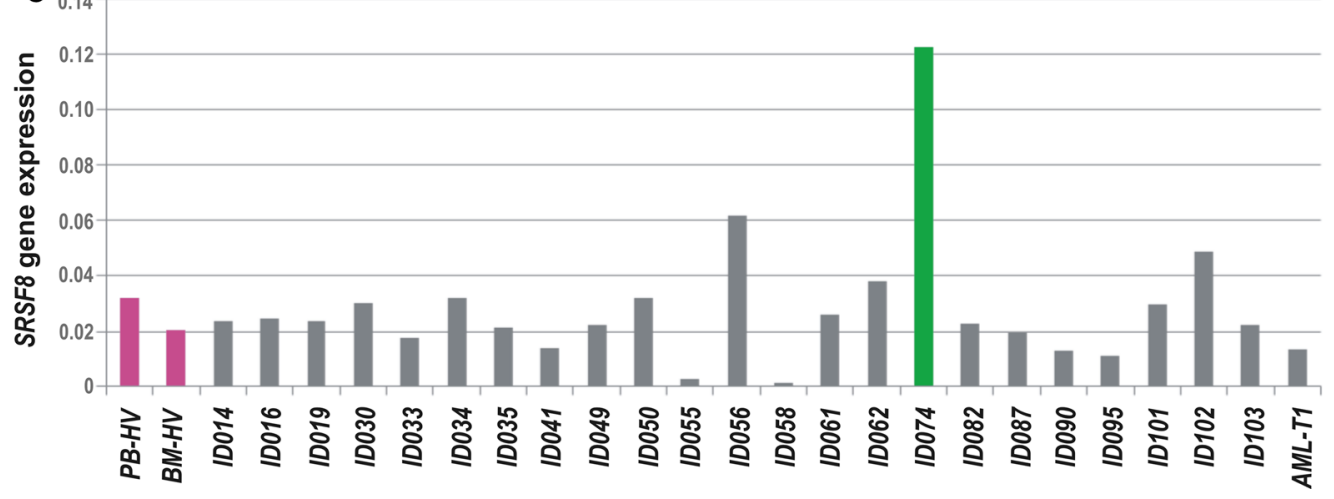



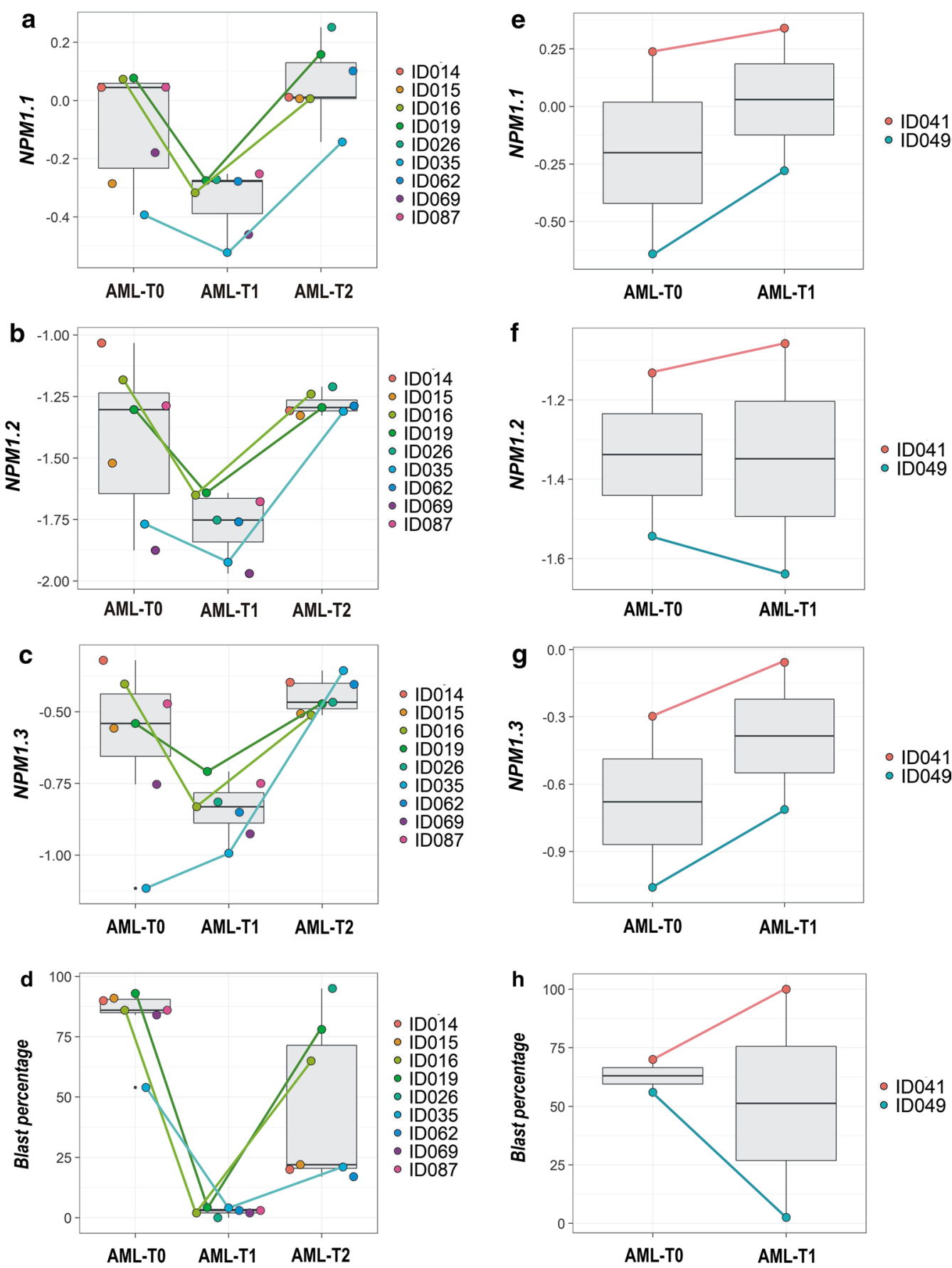

Fig. 6 The comparison of three NPM1 transcript levels in AML samples collected at three time points: T0 (at the time of first diagnosis), T1 (after treatment), and T2 (at relapse). Plots a-c present samples from patients who reached complete remission after treatment. Samples collected from the same patients at all three time points are indicated with dot-connecting lines. Plots $\mathbf{e}-\mathbf{g}$ present samples from patients who were therapy-resistant. Plots $\mathbf{d}$ and $\mathbf{h}$ present the percentage of blasts in the corresponding sample sets. Each dot represents one sample. Background boxplots show the median (a line in the middle) and the first and third quartiles (the bottom and top of the box)

the studied samples, we found the expression of six genes (SRSF2, SRSF3, SRSF4, SRSF10, SRSF11, and SRSF12) was rather decreased in AML when compared to the control
BM. For the remaining $S R S F$ genes, we did not observe substantial differences between HV and AML samples, except one AML sample (ID074 mentioned above) 
which revealed higher levels of SRSF1, SRSF2, SRSF5, SRSF7, SRSF8, and SRSF9. The most evident upregulation was observed for the SRSF8 gene (Fig. 5e). Another sample with increased SRSF8 level (ID056), presented similar aberration in NPM1.2 and NPM1.9 proportion as the ID074 sample, however, the effect was not so spectacular. It can suggest the association between NPM1 splicing dysfunction and deregulated expression of splicing-related genes.

As shown in Table 3 and Additional file 1: Figure S4, RNA-seq analysis confirmed an increase of all three protein-coding NPM1 transcripts in AML-T0 compared to HV. Moreover, we found that NPM1.9, the most abundant non-coding transcript, was also increased in AML (Additional file 1: Figure S4D). Interestingly, in AML-T1, the levels of all detected NPM1 transcripts were similar or even lower than those observed in $\mathrm{HV}$, suggesting that the level of NPM1 transcripts increases at the time of first AML diagnosis and decreases after therapy. Similarly as in the ddPCR data analysis, we noted a higher level of NPM1 transcripts in BM than PB (Additional file 1: Figure S4E-H) and in AML samples with $t(8 ; 21)$ compared to the samples without this translocation (Additional file 1: Figure S4I-L).

The discrepancies between ddPCR and RNA-seq analyses were somewhat different proportions between the levels of NPM1.1, NPM1.2 and NPM1.3 transcripts. This discrepancy most likely results from mapping short RNA-seq reads that cannot unequivocally distinguish some of the transcripts (the same exon-exon boundaries occur in different transcripts). On average, only $20 \%$ of reads were unequivocally mapped whereas $78 \%$ of reads mapped to multiple transcripts and $2 \%$ were unalignable.

\section{Analysis of NPM1 transcripts in AML samples collected after therapy and at relapse}

Because the levels of three protein-coding NPM1 transcripts were increased in leukemia compared to HV and RNA-seq data analysis suggested the decrease of NPM1 transcript level after therapy, we used ddPCR to test how the levels of three protein-coding NPM1 transcripts changed at three time points: at the time of first diagnosis (AML-T0), after therapy (AML-T1) and at relapse (AMLT2). The study included 11 patients, but samples from all three time points were available only for three patients. In total, we were able to compare 9 AML-T0, 9 AMLT1 and 7 AML-T2 samples (Table 1, Additional file 1: Table S3). The obtained results showed the decrease of all three NPM1 transcripts after therapy and an increase at relapse, to the level comparable to that observed at the time of diagnosis. A paired t-test applied for the samples collected at two time points from the same patients, showed the difference in the transcript level was statistically significant between AML-T1 and AMLT2 for all three NPM1 transcripts and between AMLT0 and AML-T2 for NPM1.1 and NPM1.2. (Additional file 1: Figure S5). NPM1 suppression after therapy was observed for all patients who reached complete remission (Fig. 6a-c). Contrary, in the case of two patients resistant to therapy, the level of NPM1 transcripts even increased in T1 time point when compared to T0 (Fig. 6e-g). The changes in NPM1 expression can be correlated with the blast percentage (and to a lesser extent with WBC count) of the samples collected at the first diagnosis, after therapy and at relapse (Fig. 6d, i). For the patients who reached complete remission, Pearson correlation coefficients for the blast percentage and NPM1.1, NPM1.2 and NPM1.3 levels measured at the three time points were equal to $0.6,0.56$ and 0.47 , respectively. For the therapyresistant patients, Pearson correlation coefficients for the blast percentage and NPM1.1, NPM1.2 and NPM1.3 levels measured at the two time points were equal to 0.6 , 0.88 and 0.62 , respectively.

\section{Discussion}

Regarding AML, only one study dedicated to NPM1 splice variants has been reported to date [31]. Although the authors showed an increase of three NPM1 transcripts in AML compared to HV, they focused mainly on the NPM1.3 transcript (R2 in their study). Our results confirmed the increase of all three NPM1 transcripts in acute leukemia. In the case of two transcripts, NPM1.1 and NPM1.3, the level of upregulation in AML vs. HV was practically the same (ratio 2.9 for NPM1.1 and 2.5 for NPM1.3 from our study versus ratios 3.15 and 2.97, respectively, from the study by Zajac et al. [31]). However, the level of NPM1.2 transcript and NPM1.2 ratio between AML and HV was much higher in the work of Zajac et al. [31]. Consequently, the proportions between particular transcripts were different than observed in our study. We show, using the highly sensitive ddPCR method, that NPM1.2 is transcribed at the lowest level compared to NPM1.1 and NPM1.3 and that the NPM1.2 level in $\mathrm{HV}$ is barely detectable.

According to Grisendi et al. [37], Ruggero et al. [38] and Falini et al. [1], aberrantly increased NPM1 can act as an oncogene, promoting cell growth through enhanced ribosome production and cell survival through cell death inhibition. Described here, increased levels of the protein-coding NPM1 transcripts in leukemia support the association of NPM1 gene expression with leukemogenesis. The lack of difference in NPM1 transcript levels between AML and ALL suggests a more general mechanism, not limited to the myeloid lineage. The role of NPM1 in oncogenesis may be additionally supported by the observed here decrease of the NPM1 transcripts after 
therapy and an increase at relapse. The decrease of the NPM1 levels upon treatment was also demonstrated in liver cancer [39], breast cancer [40] and lung cancer cells [25]. Our results suggest the decrease of NPM1 expression in a complete remission is a consequence of the blast proliferation suppression by the therapeutic agents. It is not surprising that in the therapy-resistant samples, where the number of leukemic blasts is still high, high NPM1 transcript levels are maintained.

The fact that the levels of particular NPM1 transcripts were highly correlated with each other indicates common transcriptional regulation. However, we also found some differences in the expression pattern of NPM1 transcripts. Of note, the elevated level of only one transcript, NPM1.2, was associated with the absence of an NPM1 mutation. The NPM1.3 level was higher in BM than in $\mathrm{PB}$ and seemed to be upregulated in samples with $\mathrm{t}(8 ; 21)$. Moreover, RNAseq data analysis revealed the existence of variation in the proportions of particular NPM1 splice variants between the studied samples. This can be influenced by the mutations in genes encoding splicing factors. As the co-occurrence of different mutations is often found in AML, we cannot exclude some of our patients carry spliceosome mutations. Also, mutations in canonical splice sites (exon/intron boundaries) and in splicing regulatory sequences of NPM1 may affect proportions between the alternative transcripts. To test it, exome sequencing would be necessary. However, not only mutations but also changes of splicing-related gene expression can impact the levels of alternative splice variants. For example, overexpression of alternative splicing regulator, SRSF1, detected in different cancer types, was postulated to promote cancerogenesis [36]. Interestingly, in AML, decreased expression of SRSF family members was shown [41] what is generally consistent with our observations. From the other side, SRSF1 and few other SRSF genes, were clearly increased in the AML sample with the highest level of NPM1.2 and the lowest level of NPM1.9 comparing to all other samples, AML and HV. The functions of these two NPM1 transcripts are unknown, but NPM1.2 encodes a protein similar to the most abundant NPM1 protein, with the same C-end, including region required for nucleolar localization and nucleocytoplasmic shuttling of the protein. Therefore, the functions of NPM1.1 and NPM1.2 could be similar. Contrary, NPM1.9 is a short non-coding transcript, containing only two first exons and $5^{\prime}$ part of the following intron. Translation of this transcript would generate a short fragment of the protein $\mathrm{N}$-end, linked to the oligomerization domain, responsible also for the interactions with other proteins. Other functional domains, implicated in nucleic acid and histone binding, ATP binding and ribonuclease activity, are localized in the central and C-end regions of NPM1 protein [1, 2, 33, 42]. The high level of NPM1.9, detected in both, AML and HV samples, suggests this transcript may play an important (e.g. regulatory) role at the RNA level.

Survival analysis of our patients showed that the expression level of NPM1 transcripts affected patient outcome more than the presence or absence of NPM1 mutation documented earlier $[11,43]$. The differences between survival curves drawn for patients with high and low levels of NPM1.1 and NPM1.3 transcripts were comparable to the difference between survival curves drawn for patients stratified according to the WBC count, the only clinical parameter influencing the outcome of patients from our study. Importantly, our data revealed that a high level of NPM1 transcripts correlates with worse prognosis. This finding is consistent with the report by Leotoing et al. [44], who showed that a high level of NPM1 enhances the aggressiveness of prostate tumors. Recently, the association of the high NPM1 expression with poor prognosis was also demonstrated in bladder urothelial carcinoma [45], gastric cancer [46] and glioma [47]. Surprisingly, in the study by Zajac et al. [31], the effect was opposite: low expression was associated with worse prognosis. However, this observation was limited to NPM1.3 and NK-AML patients. Therefore, the observed discrepancies between the study by Zajac et al. [31] and other studies, including ours, may be a consequence of karyotype-based patient selection. Zajac et al. [31] demonstrated a relationship between NPM1.3 transcript expression with NPM1 mutation and patient outcome only in a subgroup of NK-AML patients, constituting half of the entire studied cohort. Our study included $1 / 3$ of samples with cytogenetic abnormalities, only a few samples with normal karyotype, and for more than $60 \%$ of patients, the karyotype was unknown. The low number of NPM1-mutated samples (23\%) in our study is typical for unselected primary AML patients, for which no association between NPM1 mutation and prognosis exists. Additionally, the relation between NPM1 mutation and prognosis may be even more complex. Some authors reported no difference in the rate of complete remission between NK-AML patients with and without NPM1 mutation [48], and others noted that the impact of NPM1 mutation on prognosis could be dependent on the age of patients [10] or the presence of additional mutations, e.g., in the IDT1 gene [49]. These findings demonstrate that the influence of NPM1 mutation and expression on patient outcome should be further studied.

Our ddPCR-based analysis of three NPM1 proteincoding transcripts was supplemented with the analysis of RNA-seq data and the results were generally consistent. NGS-based transcriptome studies, which are currently extensive, can be an invaluable source of knowledge on 
alternative gene variants. The advantage of RNA-seq is localization of a gene/transcript of interest on a background of all genes transcribed in a cell. We demonstrated that the NPM1 gene and NPM1.1 transcript were among the most abundant genes and transcripts. However, due to NGS technology limitations, the results of the RNA-seq data analysis should be interpreted with caution. NPM1 is among the genes with a high number of alternative transcripts. Because many exons are shared between NPM1 transcripts, some transcripts cannot be reliably distinguished and quantified.

\section{Conclusions}

We showed that the NPM1 gene and its predominant transcripts are increased in acute leukemia when compared to healthy control samples. Furthermore, we showed that the levels of particular NPM1 transcripts are highly correlated with each other, and the expression levels of at least two of them can be associated with AML patient outcome. Our results suggest the low level of NPM1 expression predicts better prognosis. In our studied group, including AML with different karyotypes, the level of NPM1 expression affected patient outcome more than NPM1 mutation. RNA-seq data analysis revealed the spectrum of NPM1 splice variants in cells is wider than it would appear from previous studies. Aberrant proportions of particular NPM1 transcripts could be linked to abnormal expression of genes encoding alternative splicing (AS) factors.

\section{Additional file}

Additional file 1. Additional tables and figures.

\section{Abbreviations}

NPM1: nucleophosmin 1; AML: acute myeloid leukemia; NK-AML: normal karyotype AML; ALL: acute lymphoblastic leukemia; HV: healthy volunteer; FLT3-ITD: FMS-like tyrosine kinase 3-internal tandem duplication; ddPCR: droplet digital polymerase chain reaction; PBMCs: peripheral blood mononuclear cells; BMMCs: bone marrow mononuclear cells; DFS: disease-free survival; OS: overall survival; WBC: white blood cell; CR: complete remission; TPM: transcripts per million.

\section{Authors' contributions}

LH designed the research, performed all experiments, statistical analysis and wrote the manuscript. MKa recruited patients and provided clinical data. PW analyzed the RNA-seq data. MMS performed NPM1 mutation detection. ML participated in sample preparation. PK discussed the results and contributed to the final organization of the manuscript. KL participated in patient sample collection, identification of FLT3-ITD, NPM1, and RUNX1/RUNXT1 mutations, collection of clinical data and revision of molecular and cytogenetic results. $M F, K L, J B$ and MKo discussed the results. All authors corrected the manuscript. All authors read and approved the final manuscript.

\section{Author details}

${ }^{1}$ European Centre for Bioinformatics and Genomics, Institute of Bioorganic Chemistry, Polish Academy of Sciences, Noskowskiego 12/14, 61-704 Poznan,
Poland. ${ }^{2}$ Department of Hematology and Bone Marrow Transplantation, Poznan University of Medical Sciences, Szamarzewskiego 84, 60-569 Poznan, Poland. ${ }^{3}$ Institute of Technology and Chemical Engineering, Poznan University of Technology, Poznan, Poland. ${ }^{4}$ Institute of Computing Science, Poznan University of Technology, Piotrowo 2, 60-965 Poznan, Poland.

\section{Acknowledgements}

We are grateful to Anna Przybylowicz-Chalecka from the Department of Hematology and Bone Marrow Transplantation, Poznan University of Medical Sciences, for her help with the interpretation of the results of cytogenetic analysis.

\section{Competing interests}

The authors declare that they have no competing interests.

\section{Availability of data and materials}

All data generated or analyzed during this study are included in this published article and its additional file.

\section{Consent for publication}

Each person provided signed informed consent for publication of the results of the study.

\section{Ethics approval and consent to participate}

The study conformed to the ethical guidelines of the World Medical Association Declaration of Helsinki. Each patient and healthy volunteer provided signed informed consent for treatment and participation in this study. Appropriate approval was also obtained from the Bioethical Commission of the Karol Marcinkowski University of Medical Sciences.

\section{Funding}

This study was financially supported by the National Science Centre (grant no. 2017/01/X/NZ2/01906). This study was also supported by the Polish Ministry of Science and Higher Education under the SPUB (5536/E-63/SPUB/2017/1) and KNOW programs.

\section{Publisher's Note}

Springer Nature remains neutral with regard to jurisdictional claims in published maps and institutional affiliations.

Received: 17 June 2018 Accepted: 14 August 2018

Published online: 20 August 2018

\section{References}

1. Falini B. Acute myeloid leukemia with mutated nucleophosmin (NPM1): molecular, pathological, and clinical features. Cancer Treat Res. 2010;145:149-68. https://doi.org/10.1007/978-0-387-69259-3_9.

2. Lindström MS. NPM1/B23: a multifunctional chaperone in ribosome biogenesis and chromatin remodeling. Biochem Res Int. 2011;2011:195209. https://doi.org/10.1155/2011/195209.

3. Falini B, Nicoletti I, Martelli MF, Mecucci C. Acute myeloid leukemia carrying cytoplasmic/mutated nucleophosmin (NPMC + AML): biologic and clinical features. Blood. 2007;109:874-85. https://doi.org/10.1182/blood -2006-07-012252.

4. Chen W, Rassidakis GZ, Medeiros LJ. Nucleophosmin gene mutations in acute myeloid leukemia. Arch Pathol Lab Med. 2006;130:1687-92. https:// doi.org/10.1043/1543-2165(2006)130[1687:NGMIAM]2.0.CO;2.

5. Falini B, Mecucci C, Tiacci E, Alcalay M, Rosati R, Pasqualucci L, La Starza R, Diverio D, Colombo E, Santucci A, Bigerna B, Pacini R, Pucciarini A, et al. Cytoplasmic nucleophosmin in acute myelogenous leukemia with a normal karyotype. N Engl J Med. 2005;352:254-66. https://doi.org/10.1056/ NEJMoa041974.

6. Alcalay M, Tiacci E, Bergomas R, Bigerna B, Venturini E, Minardi SP, Meani N, Diverio D, Bernard L, Tizzoni L, Volorio S, Luzi L, Colombo E, et al. Acute myeloid leukemia bearing cytoplasmic nucleophosmin (NPMc + AML) shows a distinct gene expression profile characterized by up-regulation of genes involved in stem-cell maintenance. Blood. 2005;106:899-902. https://doi.org/10.1182/blood-2005-02-0560. 
7. Becker H, Marcucci G, Maharry K, Radmacher MD, Mrózek K, Margeson D, Whitman SP, Wu Y-Z, Schwind S, Paschka P, Powell BL, Carter TH, Kolitz JE, et al. Favorable prognostic impact of NPM1 mutations in older patients with cytogenetically normal de novo acute myeloid leukemia and associated gene- and microRNA-expression signatures: a Cancer and Leukemia Group B study. J Clin Oncol. 2010;28:596-604. https://doi.org/10.1200/ JCO.2009.25.1496.

8. Haferlach C, Mecucci C, Schnittger S, Kohlmann A, Mancini M, Cuneo A, Testoni N, Rege-Cambrin G, Santucci A, Vignetti M, Fazi P, Martelli MP, Haferlach T, et al. AML with mutated NPM1 carrying a normal or aberrant karyotype show overlapping biologic, pathologic, immunophenotypic, and prognostic features. Blood. 2009;114:3024-32. https://doi.org/10.1182/ blood-2009-01-197871.

9. Alpermann T, Kern W, Schnittger S, Schmid C, Kreuzer K-A, Serve H, Pielken HJ, Schmitz N, Wendtner C-M, Haferlach C, Haferlach T. Evaluation of the proposed reporting system of the European LeukemiaNet and recommendations for prognosis of acute myeloid leukemia. Leuk Res. 2013;37:197-200. https://doi.org/10.1016/j.leukres.2012.11.008.

10. Döhner K, Schlenk RF, Habdank M, Scholl C, Rücker FG, Corbacioglu A, Bullinger L, Fröhling S, Döhner H. Mutant nucleophosmin (NPM1) predicts favorable prognosis in younger adults with acute myeloid leukemia and normal cytogenetics: interaction with other gene mutations. Blood. 2005;106:3740-6. https://doi.org/10.1182/blood-2005-05-2164.

11. Schnittger S, Schoch C, Kern W, Mecucci C, Tschulik C, Martelli MF, Haferlach T, Hiddemann W, Falini B. Nucleophosmin gene mutations are predictors of favorable prognosis in acute myelogenous leukemia with a normal karyotype. Blood. 2005;106:3733-9. https://doi.org/10.1182/ blood-2005-06-2248.

12. Arber DA, Orazi A, Hasserjian R, Thiele J, Borowitz MJ, Le Beau MM, Bloomfield CD, Cazzola M, Vardiman JW. The 2016 revision to the World Health Organization classification of myeloid neoplasms and acute leukemia. Blood. 2016;127:2391-405. https://doi.org/10.1182/blood-2016-03-64354 4.

13. Vardiman JW, Thiele J, Arber DA, Brunning RD, Borowitz MJ, Porwit A, Harris NL, Le Beau MM, Hellström-Lindberg E, Tefferi A, Bloomfield CD. The 2008 revision of the World Health Organization (WHO) classification of myeloid neoplasms and acute leukemia: rationale and importan changes. Blood. 2009;114:937-51. https://doi.org/10.1182/blood-200903-209262.

14. Noguera NI, Ammatuna E, Zangrilli D, Lavorgna S, Divona M, Buccisano F, Amadori S, Mecucci C, Falini B, Lo-Coco F. Simultaneous detection of NPM1 and FLT3-ITD mutations by capillary electrophoresis in acute myeloid leukemia. Leukemia. 2005;19:1479-82. https://doi.org/10.1038/ sj.leu.2403846.

15. Scholl S, Mügge L-O, Landt O, Loncarevic IF, Kunert C, Clement JH, Höffken K. Rapid screening and sensitive detection of NPM1 (nucleophosmin) exon 12 mutations in acute myeloid leukaemia. Leuk Res. 2007:31:1205-11. https://doi.org/10.1016/j.leukres.2006.12.011.

16. Gruszka AM, Lavorgna S, Consalvo MI, Ottone T, Martinelli C, Cinquanta M, Ossolengo G, Pruneri G, Buccisano F, Divona M, Cedrone M, Ammatuna $\mathrm{E}$, Venditti A, et al. A monoclonal antibody against mutated nucleophosmin 1 for the molecular diagnosis of acute myeloid leukemias. Blood. 2010;116:2096-102. https://doi.org/10.1182/blood-2010-01-266908.

17. Oppliger Leibundgut E, Porret NA, Bienz Muggli M, Baumgartner H, Dahlhaus M, Baerlocher GM. Rapid and highly specific screening for NPM1 mutations in acute myeloid leukemia. Ann Hematol. 2013;92:173-7. https ://doi.org/10.1007/s00277-012-1617-9.

18. Marcinkowska-Swojak M, Handschuh L, Wojciechowski P, Goralski M, Tomaszewski K, Kazmierczak M, Lewandowski K, Komarnicki M, Blazewicz J, Figlerowicz M, Kozlowski P. Simultaneous detection of mutations and copy number variation of NPM1 in the acute myeloid leukemia using multiplex ligation-dependent probe amplification. Mutat Res. 2016;786:14-26. https://doi.org/10.1016/j.mrfmmm.2016.02.001.

19. Londero AP, Orsaria M, Tell G, Marzinotto S, Capodicasa V, Poletto M, Vascotto C, Sacco C, Mariuzzi L. Expression and prognostic significance of APE1/Ref-1 and NPM1 proteins in high-grade ovarian serous cancer. Am J Clin Pathol. 2014;141:404-14. https://doi.org/10.1309/AJCPIDKDLSGE26C $X$.

20. Loubeau G, Boudra R, Maquaire S, Lours-Calet C, Beaudoin C, Verrelle P, Morel L. NPM1 silencing reduces tumour growth and MAPK signalling in prostate cancer cells. PLoS ONE. 2014;9:e96293. https://doi.org/10.1371/ journal.pone.0096293.

21. Liu Y, Zhang F, Zhang X-F, Qi L-S, Yang L, Guo H, Zhang N. Expression of nucleophosmin/NPM1 correlates with migration and invasiveness of colon cancer cells. J Biomed Sci. 2012;19:53. https://doi. org/10.1186/1423-0127-19-53.

22. Wong JCT, Hasan MR, Rahman M, Yu AC, Chan SK, Schaeffer DF, Kennecke HF, Lim HJ, Owen D, Tai IT. Nucleophosmin 1, upregulated in adenomas and cancers of the colon, inhibits p53-mediated cellular senescence. Int J Cancer J Int Cancer. 2013;133:1567-77. https://doi.org/10.1002/ijc.28180.

23. Tsui $K$, Juang $H$, Lee T, Chang $P$, Chen C, Yung BY. Association of nucleophosmin/B23 with bladder cancer recurrence based on immunohistochemical assessment in clinical samples. Acta Pharmacol Sin. 2008;29:364-70. https://doi.org/10.1111/j.1745-7254.2008.00747.x.

24. Pianta A, Puppin C, Franzoni A, Fabbro D, Di Loreto C, Bulotta S, Deganuto M, Paron I, Tell G, Puxeddu E, Filetti S, Russo D, Damante G. Nucleophosmin is overexpressed in thyroid tumors. Biochem Biophys Res Commun. 2010;397:499-504. https://doi.org/10.1016/j.bbrc.2010.05.142.

25. Kim CK, Nguyen TLX, Lee SB, Park SB, Lee K-H, Cho S-W, Ahn J-Y. Akt2 and nucleophosmin/B23 function as an oncogenic unit in human lung cancer cells. Exp Cell Res. 2011;317:966-75. https://doi.org/10.1016/j.yexcr 2010.12.013.

26. Chan WY, Liu QR, Borjigin J, Busch H, Rennert OM, Tease LA, Chan PK. Characterization of the CDNA encoding human nucleophosmin and studies of its role in normal and abnormal growth. Biochemistry. 1989;28:1033-9.

27. Yun J-P, Miao J, Chen GG, Tian Q-H, Zhang C-Q, Xiang J, Fu J, Lai PBS. Increased expression of nucleophosmin/B23 in hepatocellular carcinoma and correlation with clinicopathological parameters. Br J Cancer. 2007;96:477-84. https://doi.org/10.1038/s.bjc.6603574.

28. Dergunova NN, Bulycheva TI, Artemenko EG, Shpakova AP, Pegova AN, Gemjian EG, Dudnik OA, Zatsepina OV, Malashenko OS. A major nucleolar protein B23 as a marker of proliferation activity of human peripheral lymphocytes. Immunol Lett. 2002;83:67-72.

29. Kondo T, Minamino N, Nagamura-Inoue T, Matsumoto M, Taniguchi T, Tanaka N. Identification and characterization of nucleophosmin/B23/ numatrin which binds the anti-oncogenic transcription factor IRF-1 and manifests oncogenic activity. Oncogene. 1997;15:1275-81. https://doi. org/10.1038/sj.onc.1201286.

30. Handschuh L, Kaźmierczak M, Milewski MC, Góralski M, Łuczak M, Wojtaszewska M, Uszczyńska-Ratajczak B, Lewandowski K, Komarnicki M, Figlerowicz M. Gene expression profiling of acute myeloid leukemia samples from adult patients with AML-M1 and -M2 through boutique microarrays, real-time PCR and droplet digital PCR. Int J Oncol. 2018;52:656-78. https://doi.org/10.3892/ijo.2017.4233.

31. Zajac M, Dolnik A, Stasiak G, Zaleska J, Kielbus M, Czapinski J, Schunn M, Correa SC, Glodkowska-Mrowka E, Sundaram RC, Jankowska-Lecka O, Schlenk RF, Döhner $\mathrm{H}$, et al. Analysis of NPM1 splice variants reveals differential expression patterns of prognostic value in acute myeloid leukemia. Oncotarget. 2017;8:95163-75. https://doi.org/10.18632/oncotarget.19871.

32. Hisaoka M, Nagata K, Okuwaki M. Intrinsically disordered regions of nucleophosmin/B23 regulate its RNA binding activity through their interand intra-molecular association. Nucleic Acids Res. 2014;42:1180-95. https://doi.org/10.1093/nar/gkt897.

33. Box JK, Paquet N, Adams MN, Boucher D, Bolderson E, O'Byrne KJ, Richard DJ. Nucleophosmin: from structure and function to disease development. BMC Mol Biol. 2016;17:19. https://doi.org/10.1186/s12867-016-0073-9.

34. Döhner H, Estey EH, Amadori S, Appelbaum FR, Büchner T, Burnett AK, Dombret H, Fenaux P, Grimwade D, Larson RA, Lo-Coco F, Naoe T, Niederwieser $\mathrm{D}$, et al. Diagnosis and management of acute myeloid leukemia in adults: recommendations from an international expert panel, on behalf of the European LeukemiaNet. Blood. 2010;115:453-74. https://doi. org/10.1182/blood-2009-07-235358.

35. Hindson CM, Chevillet JR, Briggs HA, Gallichotte EN, Ruf IK, Hindson BJ, Vessella RL, Tewari M. Absolute quantification by droplet digital PCR versus analog real-time PCR. Nat Methods. 2013;10:1003-5. https://doi. org/10.1038/nmeth.2633.

36. Cieply B, Carstens RP. Functional roles of alternative splicing factors in human disease: functional roles of alternative splicing factors in human disease. Wiley Interdiscip Rev RNA. 2015;6:311-26. https://doi. org/10.1002/wrna.1276 
37. Grisendi S, Mecucci C, Falini B, Pandolfi PP. Nucleophosmin and cancer. Nat Rev Cancer. 2006;6:493-505. https://doi.org/10.1038/nrc1885.

38. Ruggero D, Pandolfi PP. Does the ribosome translate cancer? Nat Rev Cancer. 2003;3:179-92. https://doi.org/10.1038/nrc1015.

39. Xu D-H, Liu F, Li X, Chen X-F, Jing G-J, Wu F-Y, Shi S-L, Li Q-F. Regulatory role of nucleophosmin during the differentiation of human liver cancer cells. Int J Oncol. 2014;45:264-72. https://doi.org/10.3892/ijo.2014.2407.

40. Duangmano S, Sae-Lim P, Suksamrarn A, Domann FE, Patmasiriwat P. Cucurbitacin B inhibits human breast cancer cell proliferation through disruption of microtubule polymerization and nucleophosmin/B23 translocation. BMC Complement Altern Med. 2012;12:185. https://doi. org/10.1186/1472-6882-12-185

41. Liu J, Huang B, Xiao Y, Xiong H-M, Li J, Feng D-Q, Chen X-M, Zhang H-B, Wang X-Z. Aberrant expression of splicing factors in newly diagnosed acute myeloid leukemia. Onkologie. 2012;35:335-40. https://doi. org/10.1159/000338941.

42. Federici L, Falini B. Nucleophosmin mutations in acute myeloid leukemia: a tale of protein unfolding and mislocalization. Protein Sci. 2013;22:54556. https://doi.org/10.1002/pro.2240.

43. Suzuki T, Kiyoi H, Ozeki K, Tomita A, Yamaji S, Suzuki R, Kodera Y, Miyawaki S, Asou N, Kuriyama K, Yagasaki F, Shimazaki C, Akiyama H, et al. Clinical characteristics and prognostic implications of NPM1 mutations in acute myeloid leukemia. Blood. 2005;106:2854-61. https://doi.org/10.1182/ blood-2005-04-1733.

44. Léotoing L, Meunier L, Manin M, Mauduit C, Decaussin M, Verrijdt G, Claessens F, Benahmed M, Veyssière G, Morel L, Beaudoin C. Influence of nucleophosmin/B23 on DNA binding and transcriptional activity of the androgen receptor in prostate cancer cell. Oncogene. 2008;27:2858-67. https://doi.org/10.1038/sj.onc.1210942.

45. Wang H, Yuan G, Zhao B, Zhao Y, Qiu Y. High expression of B23 is associated with tumorigenesis and poor prognosis in bladder urothelial carcinoma. Mol Med Rep. 2017;15:743-9. https://doi.org/10.3892/ mmr.2016.6033

46. Zhou F, Chen E, You D, Song Y, Sun Z, Yue L. Both high expression of nucleophosmin/B23 and CRM1 predicts poorer prognosis in human gastric cancer. APMIS Acta Pathol Microbiol Immunol Scand. 2016;124:1046_ 53. https://doi.org/10.1111/apm.12604.

47. Chen J, Sun J, Yang L, Yan Y, Shi W, Shi J, Huang Q, Chen J, Lan Q. Upregulation of B23 promotes tumor cell proliferation and predicts poor prognosis in glioma. Biochem Biophys Res Commun. 2015;466:124-30. https://doi.org/10.1016/j.bbrc.2015.08.118.

48. Boissel N, Renneville A, Biggio V, Philippe N, Thomas X, Cayuela J-M, Terre C, Tigaud I, Castaigne S, Raffoux E, De Botton S, Fenaux P, Dombret $\mathrm{H}$, et al. Prevalence, clinical profile, and prognosis of NPM mutations in AML with normal karyotype. Blood. 2005;106:3618-20. https://doi. org/10.1182/blood-2005-05-2174.

49. Marcucci G, Maharry K, Wu Y-Z, Radmacher MD, Mrózek K, Margeson D, Holland KB, Whitman SP, Becker H, Schwind S, Metzeler KH, Powell BL, Carter $\mathrm{TH}$, et al. IDH1 and IDH2 gene mutations identify novel molecular subsets within de novo cytogenetically normal acute myeloid leukemia: a Cancer and Leukemia Group B study. J Clin Oncol. 2010;28:2348-55. https ://doi.org/10.1200/JCO.2009.27.3730.
Ready to submit your research? Choose BMC and benefit from:

- fast, convenient online submission

- thorough peer review by experienced researchers in your field

- rapid publication on acceptance

- support for research data, including large and complex data types

- gold Open Access which fosters wider collaboration and increased citations

- maximum visibility for your research: over 100M website views per year

At BMC, research is always in progress.

Learn more biomedcentral.com/submissions 